\title{
Clinical significance of the depth of invasion in superficial Barrett's esophageal adenocarcinoma
}

\author{
Junya Oguma, Soji Ozawa, Akihito Kazuno, Miho Nitta, Yamato Ninomiya, Kentaro Yatabe
}

Department of Gastroenterological Surgery, Tokai University School of Medicine, 143 Shimokasuya, Isehara, Kanagawa, 259-1193, Japan

\section{Article Info}

\section{Article Notes}

Received: September 25, 2017

Accepted: October 13, 2017

\section{*Correspondence:}

Dr. Soji Ozawa MD, PhD, FACS

Department of Gastroenterological Surgery, Tokai University School of Medicine, 143 Shimokasuya, Isehara, Kanagawa, 259-1193, Japan; Tel: +81-463-93-1122; Fax: +81-463-956491; Email: sozawa@tokai.ac.jp

(c) 2017 Ozawa S. This article is distributed under the terms of the Creative Commons Attribution 4.0 International License.

\section{Keywords}

Superficial Barrett's esophageal adenocarcinoma

Depth of invasion

lymph node metastasis

Duplication of muscularis mucosae

\section{ABSTRACT}

Superficial Barrett's esophageal adenocarcinoma limited to the lamina propria, like other superficial cancers, is associated with almost no risk of lymph node metastasis. However, lymph node metastasis has been observed in patients with Barrett's esophageal adenocarcinoma invading the muscularis mucosae. The duplication of the muscularis mucosae is a pathological characteristic of Barrett's esophagus; however, the rate of lymph node metastasis might not differ according to the depth of invasion within the muscularis mucosae. Submucosal invasion is considered to be a risk factor for lymph node metastasis; however, many reports have suggested that submucosal invasion alone is not a risk factor but that the likelihood of lymph node metastasis increases as the number of risk factors increases. Generally, lymphovascular invasion, pathological differentiation and tumor size are also considered to be risk factors for lymph node metastasis. Previous reports have suggested that patients with superficial Barrett's esophageal adenocarcinoma limited to T1b-SM1 may have a lower risk of lymph node metastasis and might be candidates for endoscopic resection if other risk factors are negative.

\section{Introduction}

The incidence of adenocarcinoma arising from Barrett's esophagus is increasing because of the increased incidence of gastroesophageal reflux disease caused by obesity or aging ${ }^{1,2}$. Recently, surveillance ${ }^{3-6}$ and endoscopic resection $(E R)^{7-10}$ for Barrett's esophageal adenocarcinoma (BEA) have been actively investigated; however, only a few published studies have focused on the clinicopathological features of superficial BEA, and the differences between superficial BEA and superficial squamous cell carcinoma in the esophagus remain unclear. Generally, an investigation of the relationship between the depth of invasion and the prevalence of lymph node metastasis in superficial BEA has been very important for deciding the indications for ER or for additional treatments after $\mathrm{ER}^{11,12}$.

The aim of the present review was to evaluate previous reports investigating the relationship between the depth of invasion and the prevalence of lymph node metastasis in a large number of cases with superficial BEA and to consider future directions.

Clinicopathological features of superficial
adenocarcinoma invading muscularis mucosae in
Barrett's esophagus

There is almost no risk of lymphovascular invasion (LVI) and 
lymph node metastasis for superficial BEA limited to the lamina propria, similar to other superficial cancer. However, lymph node metastasis has been found in patients with BEA invading the muscularis mucosae $(\mathrm{MM})^{13}$. Duplication of the MM is a pathological characteristic of Barrett's esophagus $^{14-16}$. Abraham et al. classified 30 resected cases with BEA confined to regions of duplicated MM into three subgroups according to depth of invasion: inner MM (n = 10), between MM ( $\mathrm{n}=12)$ and outer MM ( $\mathrm{n}=8)$. No differences in the rates of LVI and lymph node metastasis were observed among these three groups ${ }^{17}$. In our review, the rate of lymph node metastasis in patients with BEA invading the MM was $6 \%$ (Table 1 ). This rate tended to be lower than that in patients with esophageal squamous cell carcinoma invading the $\mathrm{MM}^{11,17-20}$.

We previously reported a resected case with superficial BEA arising from long segmental Barrett's esophagus (LSBE). The tumor had invaded the deep layer of the MM pathologically. An erosive lesion in LSBE was initially found, and the lesion had developed into a superficial BEA with deep invasion of the MM two years later. An esophagectomy was performed (Figure 1) and no signs of LVI or lymph node metastasis were observed ${ }^{21}$. Sakaguchi et al. also reported a resected case with superficial BEA that had invaded deep into the MM. LVI was not observed pathologically, but a single metastatic lymph node was found in the lower mediastinum. The histopathological results for the resected specimen showed a poorly differentiated adenocarcinoma at the invasive front of this tumor ${ }^{22}$.

\section{Risk factors for lymph node metastasis in superficial BEA}

Some reports have suggested that invasion to the submucosa is a risk factor for lymph node metastasis ${ }^{18,23,24}$, while other reports have suggested that submucosal

Table 1. Summary of previous reports which had shown the rate of lymph node metastasis in patients with resected superficial BEA.

\begin{tabular}{|c|c|c|c|c|c|}
\hline \multirow{2}{*}{$\begin{array}{l}\text { Author } \\
\text { (year) }\end{array}$} & \multicolumn{4}{|c|}{ Depth of invasion (LN metastasis / Total cases) } & \multirow{2}{*}{ Ref } \\
\hline & T1a-DMM & T1b-SM1 & $\mathrm{T} 1 \mathrm{~b}-\mathrm{SM} 2$ & T1b-SM3 & \\
\hline Liu (2005) & $\begin{array}{l}2 / 17 \\
(12 \%)\end{array}$ & $1 / 12(8 \%)$ & - & $\begin{array}{c}9 / 25 \\
(36 \%)\end{array}$ & 18 \\
\hline $\begin{array}{l}\text { Westerterp } \\
(2005)\end{array}$ & $\begin{array}{l}1 / 23 \\
(4 \%)\end{array}$ & $\begin{array}{l}0 / 25 \\
(0 \%)\end{array}$ & $\begin{array}{c}6 / 23 \\
(26 \%)\end{array}$ & $\begin{array}{l}12 / 18 \\
(67 \%)\end{array}$ & 19 \\
\hline $\begin{array}{l}\text { Abraham } \\
\text { (2007) }\end{array}$ & $\begin{array}{c}3 / 30 \\
(10 \%)\end{array}$ & - & - & - & 17 \\
\hline $\begin{array}{l}\text { Kaneshiro } \\
\text { (2011) }\end{array}$ & $\begin{array}{l}0 / 30 \\
(0 \%)\end{array}$ & $\begin{array}{l}3 / 35 \\
(9 \%)\end{array}$ & - & - & 20 \\
\hline $\begin{array}{l}\text { Badreddine } \\
\text { (2011) }\end{array}$ & - & $\begin{array}{c}4 / 31 \\
(13 \%)\end{array}$ & $\begin{array}{l}10 / 49 \\
(20 \%)\end{array}$ & - & 11 \\
\hline Total & $\begin{array}{c}6 / 100 \\
(6 \%)\end{array}$ & $\begin{array}{c}8 / 103 \\
(8 \%)\end{array}$ & $\begin{array}{l}16 / 72 \\
(22 \%)\end{array}$ & $\begin{array}{l}21 / 46 \\
(46 \%)\end{array}$ & \\
\hline
\end{tabular}
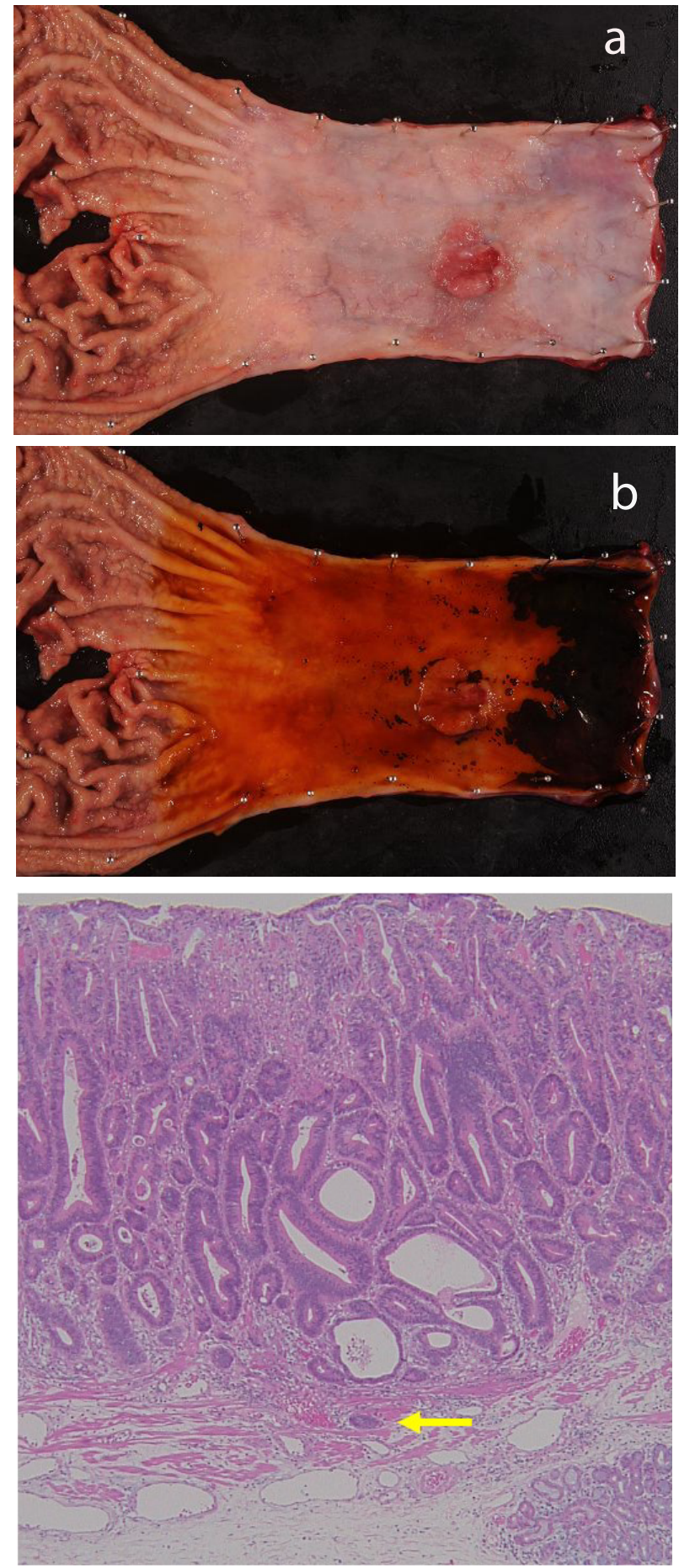

Figure 1. Resected specimen from a case with superficial Barrett's esophageal adenocarcinoma arising from long segmental Barrett's esophagus.

a. An elevated tumor was found in a region of LSBE. A slightly erosive lesion was observed in the vicinity of the tumor.

b. The squamo-columnar junction was clear when the mucosa was stained with iodine.

c. Histopathological findings using hematoxylin and eosin staining in the same case. The invasive front of the tumor extended into the outer layer of the MM (arrow) but not through the MM. 
invasion alone is not a risk factor ${ }^{19,25,26}$. Previous reports describing the rate of lymph node metastasis in patients with resected superficial BEA are summarized in Table 1. This table shows that the rate of lymph node metastasis in patients with T1b-SM1 was similar to that in patients with T1a-MM, while it was clearly lower than that in patients with T1b-SM2 or SM3. The rate of lymph node metastasis in patients with esophageal squamous cell carcinoma (SCC) confined to T1b-SM1 was approximately $20 \%{ }^{27}$, and this rate was clearly higher than that for BEA. Although the relationship between lymph node metastasis and other risk factors, such as pathological differentiation and LVI, should be evaluated, the clinicopathological features of T1b-SM1 seem to differ between BEA and SCC. Consequently, it has been suggested that the treatment strategies should also differ for each cancer. Other risk factors of lymph node metastasis are LVI, pathological differentiation and tumor $\operatorname{size}^{26,28}$. Boy et al. suggested that the likelihood of lymph node metastasis increases as the number of these risk factors in a patient increases ${ }^{26}$.

An international consensus on the classification of submucosal subgroups does not yet exist. In the Japanese classification of esophageal cancer, T1b-SM1 in surgical specimens is defined as the upper-third of the submucosal layer, while T1b-SM1 in ER specimens is defined as submucosal invasion to a depth of up to $200 \mathrm{um}$. Thus, the definition of T1b-SM1 differs between surgical and ER specimens ${ }^{29}$. On the other hand, T1b-SM1 is defined as submucosal invasion to a depth of up to $500 \mathrm{um}$ in some European countries' guidelines ${ }^{30,31}$. Caution to avoid confusing these definitions of T1b-SM1 is needed.

Although the further investigation of a larger number of cases with superficial BEA is needed, previous reports suggest that patients with superficial BEA limited to the T1b-SM1 may have a lower risk of lymph node metastasis and might be candidates for ER if other risk factors are negative.

\section{Conclusions and future directions}

According to the present review of previous reports on superficial BEA, there was no relationship between the depth of invasion and lymph node metastasis in patients with superficial BEA confined to duplicated MM in BE. Patients with superficial BEA limited to T1b-SM1 have a lower risk of lymph node metastasis and might be candidates for ER if other risk factors, such as pathological differentiation and LVI, are all negative. However, the number of previously reported cases was not sufficient to perform a statistically significant analysis. Moreover, the definition of the depth of invasion in superficial BEA remains controversial. These problems should be recognized and novel evidence should be collected from a large number of cases to ensure the development of optimal treatment strategies.

\section{References}

1. Lagergen J, Bergstrom R, Lindgren A, et al. Symptomatic gastroesophageal reflux as a risk factor for esophageal adenocarcinoma. N Engl J Med. 1999; 340: 825-831.

2. Steevens J, Schouten LJ, Goldbohm RA, et al. Alcohol consumption, cigarette smoking and risk of subtypes of oesophageal and gastric cancer: A prospective cohort study. Gut. 2010; 59: 39-48.

3. Wani S, Gaddam S. Best practices in surveillance of Barrett's esophagus. Am J Gastroenterol. 2017; 112: 1056-1060.

4. Wani S, Rubenstein JH, Vieth M, et al. Diagnosis and management of low-grade dysplasia in Barrett's esophagus: Expert review from the clinical practice updates committee of the American Gastroenterological Association. Gastroenterology. 2016; 151: 822-835.

5. Rao M, Stephen EA. Natural history of Barrett's esophagus. World J Gastroenterol. 2012; 18: 3483-3491.

6. de Jonge PJF, Steyerberg EW, Kuipers EJ, et al. Risk factors for the development of esophageal adenocarcinoma in Barrett's esophagus. Am J Gastroenterol. 2006; 101: 1421-1429.

7. Kagemoto K, Oka S, Tanaka S, et al. Clinical outcomes of endoscopic submucosal dissection for superficial Barrett's adenocarcinoma. Gastrointest Endosc. 2014; 80: 239-245

8. Chevaux JB, Piessevaux H, Jouret-Mourin A, et al. Clinical outcome in patients treated with endoscopic submucosal dissection for superficial Barrett's neoplasia. Endoscopy. 2015; 47: 103-112.

9. Terheggen $\mathrm{G}$, Horn EM, Vieth $\mathrm{M}$, et al. A randomized trial of endoscopic mucosal dissection versus endoscopic mucosal resection for early Barrett's neoplasia. Gut. 2017; 66: 783-793.

10. Osumi H, Fujisaki J, Omae M, et al. Clinicopathological features of Siewert type II adenocarcinoma: comparison of gastric cardia adenocarcinoma and Barrett's esophageal adenocarcinoma following endoscopic submucosal dissection. Gastric Cancer. 2017; 20: 663-670.

11. Badreddine RJ, Prasad GA, Lewis JT, et al. Depth of submucosal invasion does not predict lymph node metastasis and survival of patients with esophageal carcinoma. Clin Gastroenterol Hepatol. 2010; 8: 248-253.

12. Griffin SM, Burt AD, Jennings NA. Lymph node metastasis in early esophageal adenocarcinoma. Ann Surg. 2011; 254: 731-737.

13. Dunbar KB, Spechler SJ. The risk of lymph node metastases in patients with high grade dysplasia or intramucosal carcinoma in Barrett's esophagus: a systematic review. Am J Gastroenterol. 2012; 107: 850-863.

14. Takubo K, Sasajima K, Yamashita K, et al. Double muscularis mucosae in Barrett's esophagus. Hum Pathol. 1991; 22: 1158-1161.

15. Nishimaki T, Holscher AH, Schuler M, et al. Chronic esophagitis and subsequent morphologic changes of the esophageal mucosa in Barrett's esophagus: a histological study of esophagectomy specimens. Surg Today. 1994; 24: 203-209.

16. Lewis JT, Wang KK, Abraham SC, et al. Muscularis mucosae duplication and the musculo-fibrous anomaly in endoscopic mucosal resections for Barrett esophagus: implication for staging of adenocarcinoma. Am J Surg Pathol. 2008; 32: 566-571.

17. Abraham SC, Krasinskas AM, CorreaAM, et al. Duplication of the muscularis mucosae in Barrett esophagus: an underrecognized feature and its implication for staging of adenocarcinoma. Am J Surg Pathol. 2007; 31: 1719-1725.

18. Liu L, Hofstetter WL, Rashid A, et al. Significance of the depth of tumor invasion and lymph node metastasis in superficially invasive (T1) esophageal adenocarcinoma. Am J Surg Pathol. 2005; 29: 1079-1085.

19. Westerterp M, Koppert LB, Buskens CJ, et al. Outcome of surgical treatment for early adenocarcinoma of the esophagus or gastroesophageal junction. Virchows Arch. 2005; 446: 497-504. 
20. Kaneshiro DK, Post JC, Rybicki L, et al. Clinical significance of the duplicated muscularis mucosae in Barrett esophagus-related superficial adenocarcinoma. Am J Surg Pathol. 2011; 35: 697-700.

21. Oguma J, Ozawa S, Kazuno A, et al. Two-year follow-up period showing the natural history of a superficial esophageal adenocarcinoma arising in a long segment of Barrett's esophagus. Clin J Gastroenterol. 2016; 9: 289-292.

22. Sakaguchi Y, Ono S, Fujishiro M, et al. Invasive of poorly differentiated adenocarcinoma to the deep muscularis mucosae may be an indicator of lymph node metastasis in Barrett's esophageal cancer. Dig Endosc. 2013; 25: 168-172.

23. Sepesi B, Watson TJ, Zhou D, et al. Are endoscopic therapies appropriate for superficial submucosal esophageal adenocarcinoma? An analysis of esophagectomy specimens. J Am Coll Surg. 2010; 210: 418-427.

24. Dubecz A, Kern M, Solymosi N, et al. Predictors of lymph node metastasis in surgically resected $\mathrm{T} 1$ esophageal cancer.

25. Gertler R, Stein HJ, Schuster T, et al. Prevalence and topography of lymph node metastases in early esophageal and gastric cancer. Ann Surg. 2014; 259: 96-101.
26. Boys JA, Worrell SG, Chandrasoma P, et al. Can the risk of lymph node metastases be gauged in endoscopically resected submucosal esophageal adenocarcinomas? A multi-center study. J Gastrointest Surg. 2016; 20: 6-12.

27. Li B, Chen H, Xiang J, et al. Prevalence of lymph node metastases in superficial esophageal squamous cell carcinoma. J Thorac Cardiovasc Surg. 2013; 146: 1198-1203.

28. Leers JM, Demeester SR, Oezcelik A, et al. The prevalence of lymph node metastases in patients with T1 esophageal adenocarcinoma. A retrospective review of esophagectomy specimens. Ann Surg. 2011; 253: 271-278.

29. Japan Esophageal Society. Japanese classification of esophageal cancer, $11^{\text {th }}$ edition: part 1 . Esophagus. 2017; 14: 1-36.

30. The Paris Workshop. The Paris endoscopic classification of superficial neoplastic lesions: esophagus, stomach, and colon: November 30 to December 1, 2002. Gastrointest Endosc. 2003; 58 (6 Suppl); S3-43.

31. Fitzgerald RC, di Pietro M, Ragunath K, et al. British Society of Gastroenterology guidelines on the on the diagnosis and management of Barrett's oesophagus. Gut. 2014; 63: 7-42. 